\title{
Zur Radikaloperation der Leistenhernien nach Kocher.
} Von Dr. K. Hugel, Spezialarzt für Chirurgie in Landau i. d. Pfalz.

Der Aufsatz des Oberstabsarztes Dr. Doebbelin in No. 20 dieser Wochenschrift: "Zwischenfall bei der Radikaloperation einer Leistenhernie nach Kocher" gibt mir Veranlassung, eine neue Modifikation der Kocherschen Radikaloperation, wie ich sie seit Jahren ausführe, kurz mitzuteilen.

Auch ich habe die Operation nach Kocher anfangs nur bei soliden Bruchsäcken ausgeführt. Um jeden Irrtum zu vermeiden, möchte ich gleich bemerken, daß ich die von Kocher zuletzt angegebene Methode der Radikaloperation meine, wobei bekanntermaßen der Bruchsack in sich selbst eingestülpt und nicht nur durch die Faszie, sondern durch den inneren Leistenkanal zurück an einer resistenten Stelle des Bauches, oberhalb des inneren Leistenkanals, durchgezogen wird. Dabei passierte auch mir ein recht unangenehmer Zwischenfall: der Bruchsack war invaginiert, und es sollte nun der Assistent die Zange mit dem invaginierten T'eil an der inneren Bauchwand durch die kleine, etwa $1 \mathrm{~cm}$ lang gemachte Oeffnung vorstoßen, als unbegreiflicherweise der Assistent die Zange öffnete und beim Wiederschließen den Bruchsack nicht mehr fand. Das Ereignis war sehr fatal, da vom äußeren Leistenring aus der Bruchsack nicht mehr aufzufinden war; nur eine Laparotomie wäre zur Auffindung des irgendwo hineingeschobenen Bruchsackes übrig geblieben. Zur Laparotomie war mir aber das ganze Milieu, in welchem ich gerade operierte (schlechte Krankenhausverhältnisse etc.), nicht geeignet. Ich entschlo $B$ mich daher, den eingeschobenen Bruchsack in Ruhe zu lassen und Kochers Pfeilernaht der Faszie anzuschließen. Die Hautwunde wurde nach Kochers Vorgehen drainiert. Der Fall heilte schließlich nach Ueberstehung eines retroperitonealen $\mathrm{Ab}$ szesses aus und blieb sogar rezidivfrei - er verursachte mir aber eine Reihe schlafloser Nächte.

Wie erstaunt war ich, als ich auf einer Studienreise in Bern Kocher selbst dozieren hörte, daß er seine Methode nur bei den dünnen Bruchsäcken, nach Kochers Ausdruck: „die sich wie ein Condom herausoperieren lassen ${ }^{*}$, anwendet; die Methode führt also Kocher hauptsächlich bei jungen Individuen und bei frischen Hernien aus, die noch nicht lange durch ein Bruchband schwielig verändert sind; er schließt alle verdickten Bruchsäcke von seiner Methode aus. Dadurch wird auch sofort klar, warum Kocher den Bruchsack nicht eröffnet, weil er eben durch die dünnen Häute hindurch jede Spange, überhaupt jeden suspekten Inhalt sofort erkennt. Netzverwachsungen aber, die dem inneren Leistenring auflagern, werden sich durch Widerstand bei der Invagination zu erkennen geben; Netzverwachsungen, die oberhalb des inneren Leistenringes am Bruchsack liegen, werden, sofern sie mit hervorgestülpt werden könnten, außerhalb des Invaginatums zu liegen kommen, wo sie, auch bei kleinen Verhältnissen, nicht übersehen werden.

Last not least bleibt jedem Operateur, der nicht die Schulung Kochers besitzt, ein unangenehmes Gefühl, wenn die Invagination nicht glatt vor sich geht, und er kann oft im Zweifel sein, ob er nicht zu seiner Beruhigung eine Laparotomie anschließen soll. Um größere Sicherheit bei Ausführung dieser vorzüglichen Invaginationsmethode nach Kocher zu erreichen, schlage ich vor, bei den Hernien, die sich nach dem oben Gesagten nach Kochers Methode operieren lassen, den Bruchsack an der Spitze zu öffnen, mit dem Finger den ganzen Bruchsack, inklusive des inneren Leistenringes, von innen aus abzutasten, die Inzision mit einem dünnen Katgutfaden mit einigen Stichen zu verschließen und den Faden lang zu lassen. Alsdann erfolgt die Invagination nach Kocher, wobei der an der Spitze genähte Bruchsack, der beim Durchziehen durch die Bauchdecken nun von innen zu Gesicht kommt, die Naht von innen an der Spitze zeigt. Durch das ganze Invaginatum läuft der Katgutfaden; man kann nun an der Basis des Invaginatums ebenso leicht eine Quetschzange anlegen, als wenn kein Faden durch dasselbe 
liefe. Nach Abnahme der Quetschzange durchsticht man die Quetschfurche und zieht jetzt vor dem Knüpfen des Fadens den Leitfaden in dem Bruchsack entweder oben oder unten heraus. Bei dieser Modifikation passierte uns während der letzten fünf Jahre kein Zwischenfall mehr. Man kann jederzeit den halb eingestülpten Bruchsack an dem Katgutfaden wieder herausholen; man ist keinen Augenblick mehr im Zweifel über die Verhältnisse am Innenrand des Leistenringes und hat trotzdem die vorzügliche Methode nach Kocher ausgeführt. Rezidive beobachtete ich bei dieser Modifikation nicht häufiger als bei der ohne dieselbe ausgeführten Kocherschen Operation. 